\title{
Features of actualization of stylistic marking of nouns in artistic speech
}

\author{
L. R. Sidorkova ${ }^{1}$, Kh. A.Aripova ${ }^{2}$ \\ ${ }^{l}$ c.ph.s, associate Professor of the Department of Russian language and literature, Bukhara \\ state University, Uzbekistan \\ ${ }^{2}$ Candidate of pedagogic Sciences, associate Professor of the Department of Russian language \\ and literature, Bukhara state University, Uzbekistan
}

Email: sidorkova1@umail.uz

\begin{abstract}
The article presents a comparative analysis of stylistic marking of nouns in language and speech on the material of data of explanatory dictionaries of the Russian language and works of M. Bulgakov.

Keywords: actualization, stylistic marking, language, speech, explanatory dictionary, lexicography, vocabulary litter, double and triple litters, functional and stylistic coloring, emotional and expressive coloring, idiolect, artistic speech.
\end{abstract}

\section{INTRODUCTION}

The vocabulary of a language is a complex hierarchical system of lexical units that are part of individual lexicons. Russian linguists consortium of St. Petersburg and Moscow is currently working on the creation of a National corpus of the Russian language, which "should be universal in terms of the representation of texts of different genres, which, we can assume, reflect the characteristics of the current state of the Russian language in its development" [3, P. 2]. However, so far no dictionary of the language and even the sum of all dictionaries do not reflect the total mass of lexical units actually existing in idia-lexicons and their stylistic coloring. Based on the observation of the speech activity of individuals, the development of special ways of selecting units of this activity, dictionaries of language are not a mechanical sum of idiolects, and typed and classified phenomena, which still do not lose their connection with the real basis. If this is so, then it is possible to compare the dictionary of the language (society) and the dictionary of a particular native speaker, and to clarify the features of the latter (in our case - the language of the writer), one can start from the vocabulary of the entire language system fixed by existing dictionaries.

\section{THEORETICAL BACKGROUND}

At the same time, we should not forget that the word in the context of a work of art is not always identical with its linguistic equivalent in the dictionary, since "it no longer becomes a wordrepresentation, but an exponent of an artistic image (a word-an artistic image); it appears qualitatively and semantically transformed as a result of artistic-figurative speech concretization" [4, P.118]. Consequently, the data of dictionaries and literary texts reflect the features of different types of thinking: conceptuallogical and figurative-poetic.

In recent years, more and more data have been accumulated in linguistics to support the hypothesis that every native speaker subconsciously has knowledge of the relative probabilities of the use of words in speech in a given language and of the different probabilities of the connection of words in the process of language communication. And this knowledge is constantly used by a person when one of the many ways of organizing a statement is chosen. The choice is due to a large number of factors of both linguistic and extra-linguistic order. "Certain sets of language elements with their probabilities can be conditionally called the style of language. The functioning of these aggregates will be a style of speech. In 
the very process of functioning of the language style appears the new features to the style of speech appear" [5, P. 197]. Such sets of language elements can differ both in qualitative characteristics and in their quantitative ratio in the process of communication.

The subject of our study on the lexicographical level are normative explanatory dictionaries: "Dictionary of modern Russian language" D.N.Ushakov in 4 volumes (hereinafter TSU), and "Dictionary of Russian language" S.I. Ozhegova, and N.Yu.Shvedova (then SO).

\section{LITERATURE REVIEW}

In our study of the speech realization of types and types of stylistic coloring of the noun, we stopped at the work of M. A. Bulgakov. This is explained by the following reasons.

First, comparative studies of language and speech is most convenient to carry out on the material of prose works, which, unlike poetic, with their specific structure and content, the requirements of rhyme and rhythm, closer to the usual sounding speech. Prose, as a rule, reflects the main features and linguistic trends, the influence of his era.

Secondly, the life and career of M. A. Bulgakov (1891-1940) chronologically coincides with the period of collection of material and the release of the dictionaries under consideration: TSU (I edition from 1935 to 1940), CO( I edition in 1949), which is a condition of compliance with the principle of historicism, necessary in the study of any social phenomenon, including the LANGUAGE - SPEECH dichotomy.

Thirdly, M. A. Bulgakov is the largest writer of the first half of the XX century with versatile talents: he was both a journalist and a writer, and a satirist and a tragedian, and a realist and a fantasist. Therefore, in our opinion, the analysis of examples from different in genre, volume, subject and time of creation of works of this author is productive.

Fourth, the work of M. A. Bulgakov for a long time was in disgrace, and many of his works became available to a wide audience much later than the death of the author: the play "Run" (1926-1928) staged in 1957., unfinished "Theatrical novel" (1936-1937) published in 1965, the novel "the Master and Margarita" (1929-1940) was published in 1966-1967, the story "heart of a Dog" (1925) published in 1987. from a linguistic point of view, it is currently very relevant.

\section{MAIN PART}

According to our observations, in most examples the stylistic coloring of words in language and artistic speech coincides. Differences more often concern features of stylistic characteristics of words in explanatory dictionaries (if to exclude the facts of absence of a number of lexemes in them).

So, if a word in the dictionary (dictionaries) has a double (triple) mark, then in speech only one stylistic index is usually updated. For example: the noun muzzle in the meaning of "face" in TSU is characterized as vulgar, and in CO has a double mark " Prost.abusive.". In M. A. Bulgakov's "Diavoliad", "the good and humiliated Dyrkin" speaks of himself:

"You don't get enough sleep, you don't finish, you don't finish, and the result is always one in the face...well... Dyrkina Beat, beat! Muzzle have him, in sight, breech [2, P. 29].

In this context, the vernacular stylistic coloring of the word is realized, and its expletive value is obscured, firstly, by the content of Dyrkin's complaint and its tone, and secondly, by what the hero says about himself. Of the varieties of the two types of stylistic coloring (functional-stylistic and expressivze-emotional), the most important in this situation was the functional-stylistic coloring.

The noun starushonka (old woman) in TSU is marked as colloquial, and in CO-as a pejorative colloquial. In the story of M. A. Bulgakov "Water of life", which tells about hopeless drunkenness in the railway village and the struggle of its inhabitants for the opportunity to buy a drink in the shop, the case is described as an old woman tries unsuccessfully to get into the queue to buy meat. But the queue, thirsty for alcohol, does not miss it.

A confused old woman with a bottle of vegetable oil rushed from the flank to the organized queue repeated attacks,-

M. A. Bulgakov wrote [2, P. 129], focusing on the helplessness of an elderly woman and, thus, on the pejorative shade of the stylistic coloring of the noun old woman. In this case, the context actualizes the expressive and emotional coloring of the word. 
Inconsistencies in the stylistic qualification of words are observed when in one dictionary the word has a stylistic mark, and in another it does not. In artistic speech, in such cases, the word often appears as marked. For example, describing in the "Diavoliad" by Korotkov's meeting with Kalsoner, M. A. Bulgakov noted:

Korotkov recognized everything: the gray jacket, the cap, and the raisins of his eyes... and then, in the picture of Kalsoner's disappearance in the Elevator, he wrote:

The legs disappeared first, then the belly, the beard, the eyes, and the eyes, mouth [2, p. 14].

From the comparison of Kalsoner's eyes with the highlights, it is clear to us that they were small. Therefore, the shape of the eyes further in the text we perceive as a diminutive, at that time, as in the trailer she was without a litter. CO characterizes this noun as a diminutive not by means of stylistic marking, but by italics, as an addition to the interpretation.

And, finally, differences arise as a result of a simple mismatch of stylistic qualification of individual words in different explanatory dictionaries. In such cases, indicators of different dictionaries can be implemented in different contexts. Thus, the noun woman in the trailer is labeled as "Speech. vulg.", and in $\mathrm{CO}$ as " is simple.". In "Diavoliad" by Bulgakov read:

A wrinkled brown woman came out with empty buckets ...

$>$ Baba! Woman!- anxiously cried the doctor."Where's the Bureau?"

$>$ I do not know, father, I do not know, the breadwinner, - the woman answered [2, P. 23].

In this passage, the stylistic halo of the word Baba does not contain a high degree of reduction and coarseness, so its stylistic coloring can be assessed as vernacular.

In the painful dream of Alexei Turbin (novel "White guard"), the word Baba, used in the speech of Sergeant Zhilin, abounding in coarse vocabulary, gets a vulgar coloring:

- ...Women, speaking in confidence, some stuck on the road ... Women turn temporarily, and there it will be visible... and the Apostle Peter ... eyes-splash, and I see that he also saw women on carts [1, P. 56].

As examples show, the word Baba, like many others, is characterized in speech by a syncretism of shades of stylistic coloring. The authors of different explanatory dictionaries, trying to distinguish the dominant from them, rely on their own linguistic intuition, personal experience, making a share of subjectivism in the stylistic characteristic of lexemes. This is one of the main reasons for the mismatch of stylistic droppings in different dictionaries.

Another reason is that a word in one explanatory dictionary can be characterized from the point of view of functional-stylistic, and in another - from the point of view of expressive-emotional. For example, the noun Affairs at TSU is marked as "Accel.FAM", and co - as "uniting". In speech, usually all pejorative words are colloquial. In M. A. Bulgakov's novel "Fatal eggs" the noun delishki (problem) is included in the following context:

Visited Professor two times from the Kremlin, Yes once there were students whom Persikov examined... for all these Affairs the Professor did not notice three days [2, P.53].

From the content of the passage it follows that everything that happened in three days has no special meaning for the hero. It was important for the author to show that the whole life of the Professor is subordinated to one main goal - science. So in the story actualize area pejorative expressive-emotional connotation of the noun. Therefore, such words should be provided with either double (triple) litters, or mandatory litters of expressive and emotional nature, implying a corresponding functional and stylistic coloring.

In addition to all the above, the discrepancy in the linguistic and textual stylistic coloring of lexemes may concern those cases when there is an author's" increment " of meaning and / or a change in the stylistic coloring of words.

\section{CONCLUSION}

Thus, the comparative analysis of stylistic coloring of a noun in explanatory dictionaries and M. A. Bulgakov's artistic speech showed the following.

First, the writer uses in his works only a small part of the stylistically colored substantive vocabulary of the language, and the composition of its types and types of marking in language and speech does not coincide. 
Secondly, the expressiveness of artistic speech is caused not only by its saturation with stylistically marked means, but also by the writer's ability to combine these means into an organic unity with the whole context in accordance with the tasks set.

Thirdly, despite the fact that in most cases the stylistic coloring of words in language and speech coincides, there are a number of differences between the data of dictionaries and works of art. This may be due to the presence in dictionaries of double (triple) litters and actualization in the context, as a rule, only one meaning, as well as a discrepancy in the stylistic qualification of words already at the lexicographic level.

\section{REFERENCES}

1. Bulgakov M. Favorites. - Tashkent: Uzbekistan, 1989.

2. Bulgakov M. Notes of the deceased. - Tashkent: Ed. literature and art. Gafur Gulyama, 1990.

3. Ventsov A.V., Kasevich V. B., Yagunova E.V. Corpus stratification and dictionary hierarchy. // II International Congress of Russian Studies-researchers: Abstracts. doc. - M., 2004. http://www.philol.msu.ru

4. Kozhina M.N. On the speech systematic nature of the scientific style in comparison with some others. - Perm: Perm State University, 1972.

5. Muratova V.M. A statistical description of the style differentiation of active vocabulary (based on the materials of the "Frequency Dictionary of the Modern Russian Language") // Sat. Questions of statistical style. - Kiev: Naukova Dumka, 1974. 